\title{
The relationship between perceived time pressure and food practices among UK adults in employment
}

Time pressure or lacking time is often a reported barrier to cooking at home ${ }^{(1,2)}$. This study aimed to examine the relationship between perceived time pressure and food practices among UK adults in employment.

A questionnaire survey was used to collect data on perceived time pressure, frequency of engaging in different food practices for evening meals, and socio-demographic characteristics. A Time Pressure Score (TPS) was created by combining five statements about feeling rushed and hurried, being time poor, being unable to take a day off and satisfaction with pace of life. The TPS ranged from 1-7 with a higher score indicating greater perceived time pressure. Separate linear models were used to assess associations between TPS and frequency of engaging in each food practice, adjusting for covariates number of hours worked, age, gender, education, household income and living with children. The Bonferroni correction for eight multiple comparisons was performed and values were considered statistically significant if $p<0.006$.

The final sample comprised 770 UK adults (19-65 years) in paid employment. Mean (SD) TPS was 4.1 ( \pm 1.4$)$ and hours worked per week was 36.4 hours $( \pm 8.8)$. Although $68.7 \%$ of respondents agreed that their job was the main cause of time pressure, TPS was not associated with hours worked. Evening meals were eaten daily by $84.7 \%$ of the sample. TPS was negatively associated with frequency of cooking meals at home $(B=-0.163,95 \% \mathrm{CI}-0.269--0.057, p=0.003)$ and cooking complex meals that take a lot of time $(\mathrm{B}=-0.115,95 \% \mathrm{CI}-0.184--0.047, p=0.001)$. Conversely, TPS was positively associated with frequency of cooking quick meals $(\mathrm{B}=0.216,95 \%$ CI $0.136-0.295, p<0.001)$, having ready-meals $(\mathrm{B}=0.151,95 \% \mathrm{CI} 0.080-0.222, p<0.001)$, having takeaways $(\mathrm{B}=$ $0.074,95 \%$ CI $0.038-0.111, p<0.001)$ and replacing meals with snacks $(\mathrm{B}=0.071,95 \% \mathrm{CI} 0.033-0.109, p<0.001)$. There were no statistically significant associations between TPS and eating meals out $(\mathrm{B}=-0.012,95 \% \mathrm{CI}-0.041-0.018, p=0.437)$ or skipping meals $(\mathrm{B}=0.044,95 \%$ CI $0.003-0.085, p=0.034)$.

Findings from the present study suggest that perceived time pressure may be a barrier to cooking at home and key driver of convenience food consumption e.g. ready meals and takeaways. This could have adverse dietary consequences for those under time pressure who rely on processed foods that can have poor nutritional quality. Time pressure was not associated with eating out which may be more of a social activity that is done rarely compared to other food practices. Future research should explore strategies to help busy adults in employment to maintain healthy food practices.

1. Larson NI, Perry CL, Story M, et al. (2006) J Am Diet Assoc 106, 2001-2007.

2. Horning ML, Fulkerson JA, Friend SE, et al. (2017) J Nutr Educ Behav 49, $60-66$. 